\title{
24-year-old Male patient Diagnosed with Intramucosal Signet Ring Cell Gastric Cancer with Molecular Analysis: A Case Report
}

\author{
(1) Mehtap EROĞLU,' (1) Dilara Fatma AKIN BALi,' ${ }^{\text {(D) Sedef Hande AKTAŞ, }{ }^{3} \text { (D) Teoman KANKILIÇ }}$ \\ 'Department of Pathology, Niğde Ömer Halisdemir University, Faculty of Medicine, Niğde-Turkey \\ 2Department of Medical Biology, Niğde Ömer Halisdemir University, Faculty of Medicine, Niğde-Turkey \\ ${ }^{3}$ Department of Program of Medical Laboratory Techniques, Eskişehir Osmangazi University, Vocational Scholl of Health Services, \\ Eskişehir-Turkey \\ ${ }^{4}$ Department of Biotechnology, Niğde Ömer Halisdemir University, Faculty of Science Literature, Niğde-Turkey
}

\section{Introduction}

Gastric cancers are the fifth most commonly diagnosed cancer in the world, but they are the third among the cancer-related deaths, according to the 2018 World Health Organization data. [1] In Turkey, gastric cancer is the second cause of cancer-related deaths in men and third in women. [2]

More than $95 \%$ of gastric cancers are adenocarcinomas, whereas $5 \%$ are lymphomas, leiomyosarcomas, and less commonly carcinoid tumors, carcinosarcomas, and squamous cell carcinomas.[3] Signet ring cell carcinoma (SRCC), a type of gastric adenocarcinoma, is a cohesive type of cancer and is characterized by cytoplasmic mucin secretion and crescent-shaped cells. SRCC is frequently diagnosed in people aged 50 and over and its incidence increases over age 70. SRCC is very rare to be seen under the age of thirty $(0,5 \%)$. [4] Compared with other types of gastric cancer, the clinicopathological features of SRCC are reported to be 
different. In general, even though this type of cancer is thought to be more aggressive and has a worse prognosis than other types of gastric cancer, it is stated that there are uncertainties regarding the characteristics and survival outcomes. $[5,6]$

Since the diagnostic tools used in patients with SRCC have low sensitivity and specificity in diagnosis and prognosis, it is important to support diagnosis, treatment follow-up, and relapse by molecular genetic biomarkers.

The p53 tumor suppressor gene (17p13.1) located in the $\mathrm{p}$ arm of chromosome 17 encodes a 393 amino acid long nuclear phosphoprotein that weighs $53 \mathrm{kDa}$. [7] p53, which acts as a transcription factor, initiates a gene expression program that will prevent proliferative propagation of the damaged cell by being activated after many disorders in the cell, such as DNA damage, hypoxia, viral transformation, oncogene activation, spindle damage, nucleotide disorder. Thus, it protects the organism against cancer development. [8] The p53 tumor suppressor gene has been studied in many cancer studies and has been found to mutate in more than $50 \%$ of solid tumors. As with gastric cell lines and early gastric cancers, loss of heterozygosity (LOH) and p53 gene mutation on chromosome $17 \mathrm{p}$ is frequently observed in advanced gastric cancers. [9] TP53 (42\%) has been reported to be the most frequently mutated gene in SRCC. [10]

Many studies have shown that 350 kilobase- long $\mathrm{NF} 1$, expressed as one of the largest genes in the human genome and classified as a tumor suppressor gene, plays an important role in many cancers, such as brain tumors, breast cancer, sporadic colon cancer, lung cancer, and ovarian tumors. [11] However, the relationship between gastric cancer and NF1 is not fully known. Recent studies have shown that NF1 is a tumor suppressor that plays a critical role in many cancers and has been identified as a prognostic value for GC patients. [11] NF1 is caused by mutations in the Nf1 gene in the $17 \mathrm{q} 11.2$ region of chromosome 17 and the product of the gene is the cytoplasmic protein "neurofibromin". [12] The region of neurofibromin which includes exon 21-27a, converts Ras-GTP to Ras-GDP and inactivates it. Loss of neurofibromin leads to continuous cellular activation of the mitogenic Ras signaling pathway and cell proliferation. The Nf1 gene is classified as a tumor suppressor gene due to its interaction with Ras. $[13,14]$

The aim of this case report is to determine the possible mutations of TP53 and NF1 genes known as tumor suppressors and to determine whether they can be used as patient-specific prognostic genetic biomarkers in the pathogenesis of SRCC at an early age.

\section{Case Report}

A 24-year-old male patient was admitted to our center with complaints of epigastric pain, fatigue and weight loss for six months. The patient reported no change in gastrointestinal complaints of nausea, vomiting, bloating, gastrointestinal bleeding or changed bowel movements. It was understood that the patient had a history of a $20 \mathrm{~kg}$ weight loss over the past six months before applying to our center. The patient stated that he had not undergone any surgery and had not used any medication, alcohol or derivatives or cigarettes. There was no family history of cancer. Physical examination revealed signs of epigastric tenderness and weight loss, and pathological lymph nodes could not be palpated. Pulmonary and cardiologic examinations were normal. The shape of the abdomen was flat, but there was minimal splenomegaly on palpation. Bowel sounds were normal during auscultation. No abnormality was observed in the rectal examination. Laboratory tests showed microcytic anemia (Hb: $9.1 \mathrm{~g} / \mathrm{dL}$, Hct: 28.9\%, MCV: $72.6 \mathrm{fL}$ ).

\section{Upper GI Endoscopy}

An ulcerated mass lesion, which caused pyloric deformity and gastric outlet obstruction, and abundant bile secretion in the stomach were reported. The upper abdominal CT examination revealed bronchopneumonic infectious infiltration findings in the basal segments of the lower lobe of both lungs and in the lingular segment of the left upper lobe. The appearance of the liver, gall bladder and bile ducts were normal. The spleen was larger than normal, its long axis was $18 \mathrm{~cm}$ in length and parenchyma density was homogeneous. Pancreas and bilateral kidneys were normal. No retroperitoneal or intraabdominal LAP was detected. There were heterogeneity and contamination in the abdominal mesenteric adipose tissue, as well as a minimal fluid effusion between the intestinal loops. The stomach was larger than normal and appeared dilated and distended. Clinical evaluation was recommended for the narrowing in the gastric outlet (Fig. 1a-b).

\section{Lower Abdominal CT Examination}

No gross pathology associated with bladder was observed. Millimetric dystrophic calcifications were observed in the central zone of the prostate gland. Pelvic large vessels were normal and no pelvic LAP was detected. As a result of this physical examination and laboratory findings, subtotal gastrectomy was performed and the material was sent to the pathology department.

Microscopic examination: In HE-stained sections, a tumor consisting of TYH starting from mucosa and 

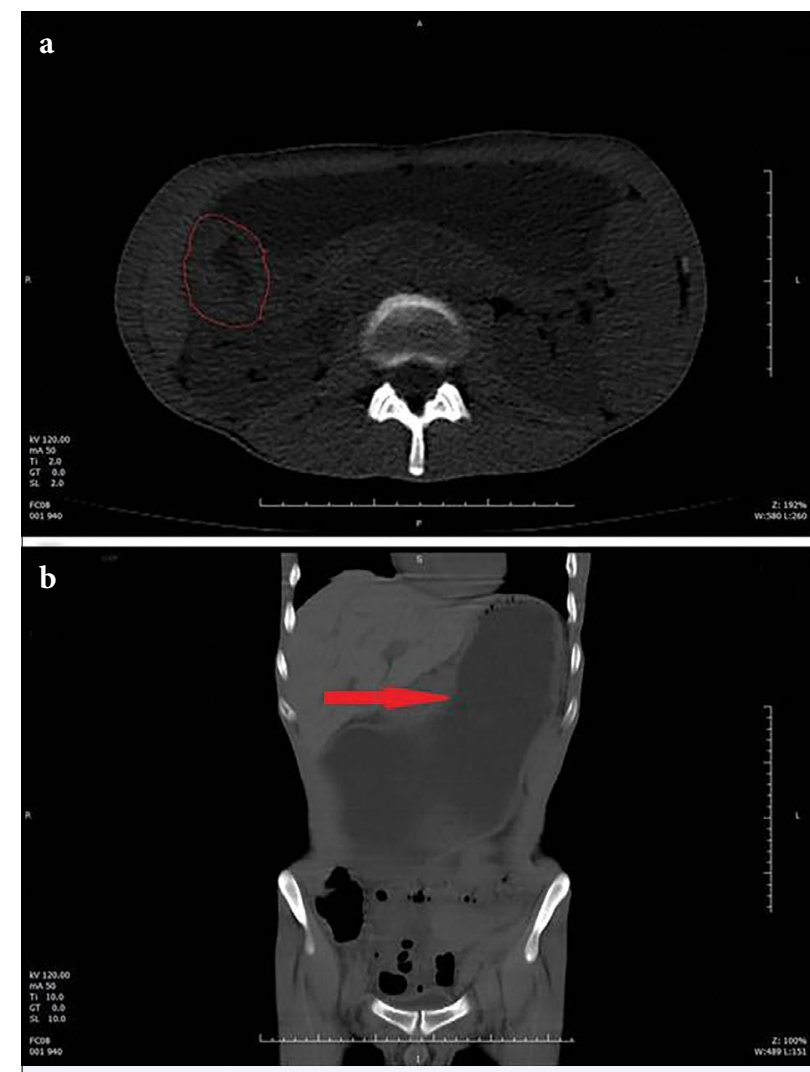

Fig. 1. (a) Sagittal section of abdominal CT: Dilated stomach appearance (b) Abdominal CT axial section: Pyloric mass appearance.

extending to the serosal surface was observed (Fig. 2a). The inflammatory response was mild, and there was a lymphovascular and perineural invasion. A total of 21 metastatic lymph nodes were detected. No Helicobacter pylori were observed with Giemsa stain. There is no intestinal metaplasia in the non-tumor mucosa Cytoplasmic staining was observed in tumor cells with PAS-AB and mucicarmine stains (Fig. 2b-c). Considering the histomorphological findings, the case was diagnosed as a signet ring cell carcinoma (SRCC) pT4aN3bMx.

\section{Mutation Analysis}

For mutation analysis, DNA was isolated from the tissue sample obtained from the patient using a commercial DNA isolation kit. Approximately 200 ng of DNA was used as a template for PCR amplification. Total volume of reaction mix was $25 \mu \mathrm{L}$, which comprised of $16.75 \mu \mathrm{L}$ sterile water, $2.5 \mu \mathrm{L}$ reaction buffer $(750 \mathrm{mM}$ Tris- $\mathrm{HCl} \mathrm{pH} 8.8$ at $25^{\circ} \mathrm{C}, 200 \mathrm{mM}\left(\mathrm{NH}_{4}\right)_{2} \mathrm{SO}_{4}, 1 \mu \mathrm{L}$ dNTP mix (A, C, G, T $200 \mathrm{mM}), 1.25 \mu \mathrm{L} \mathrm{MgCl} 2(25$ $\mathrm{mM}), 1 \mu \mathrm{L}$ forward and reverse primers (10 pmol), 0.5

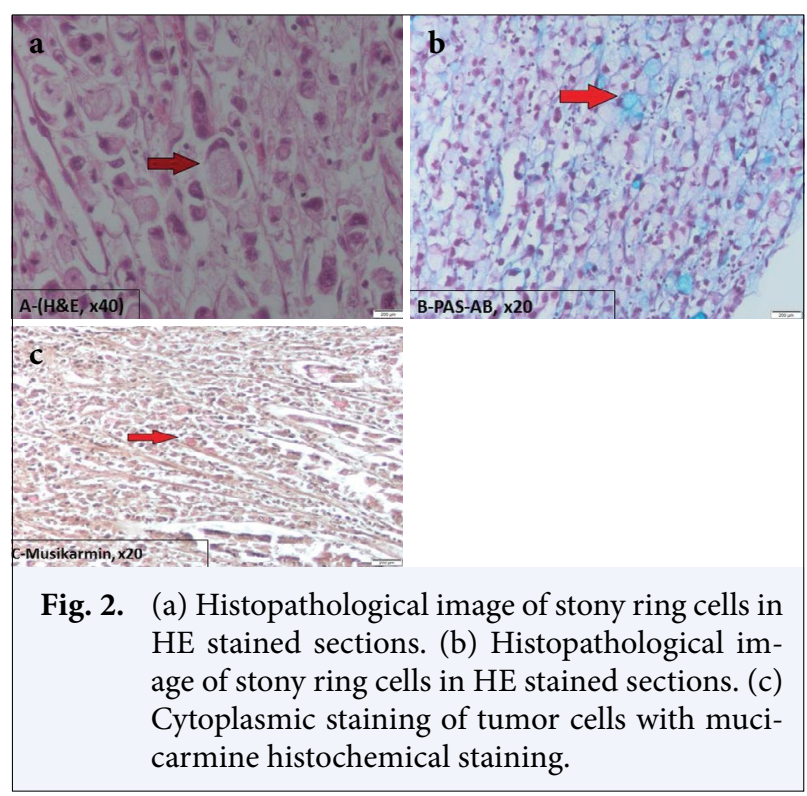

$\mu \mathrm{L}$ Taq polymerase (500 U, Fermentas) and $1 \mu \mathrm{L}$ template DNA Amplification reactions were performed using Applied Biosystems Veriti VR 96-Well Thermal Cycler and started with an initial denaturation step at $94{ }^{\circ} \mathrm{C}$ for $5 \mathrm{~min}$, followed by 40 cycles of denaturation for $45 \mathrm{~s}$ at $94^{\circ} \mathrm{C}$, primer annealing for $1.5 \mathrm{~min}$ at 56-58 ${ }^{\circ} \mathrm{C}$, extension for $1.5 \mathrm{~min}$ at $72^{\circ} \mathrm{C}$ and final extension for $10 \mathrm{~min}$ at $72{ }^{\circ} \mathrm{C}$. After amplification, PCR products were run on $2 \%$ agarose gel containing GelRed in $1 \mathrm{xTAE}$ for 40 minutes at $90 \mathrm{~V}$. Thermo Scientific Gene Ruler 100 bp DNA Ladder was used as a marker. Subsequently, all gels were visualized using KODAK Gel Logic 100 System. PCR products were sequenced using the ABI 3500 XL DNA Sequencer. Data were analyzed using Data Collection Software and Chromas 2.6.5 (Technelysium) to determine sequence variations in comparison to reference TP53 (Exon 4) and NF1 (Exon 21) sequences from Ensemble genome browser.

\section{Results}

As a result of the mutation analysis, a total of $14 \mathrm{mu}-$ tations were identified, (Ensembl: ENSG00000141510 MIM:191170) nine in the TP53 gene known as a tumor suppressor and (Ensembl: ENSG00000196712 MIM:613113) five in the NF1 gene. All detected changes were previously recorded in the HGMD edatabase. The changes detected in the TP53 and NF1 genes are shown in the electropherogram images presented in Figure 3. All of the changes detected in the TP53 gene (p.P72R, p.P75H, p.P77L, p.A78T, p.A79T, p.A80G, p.P85N) caused amino acid change due to 


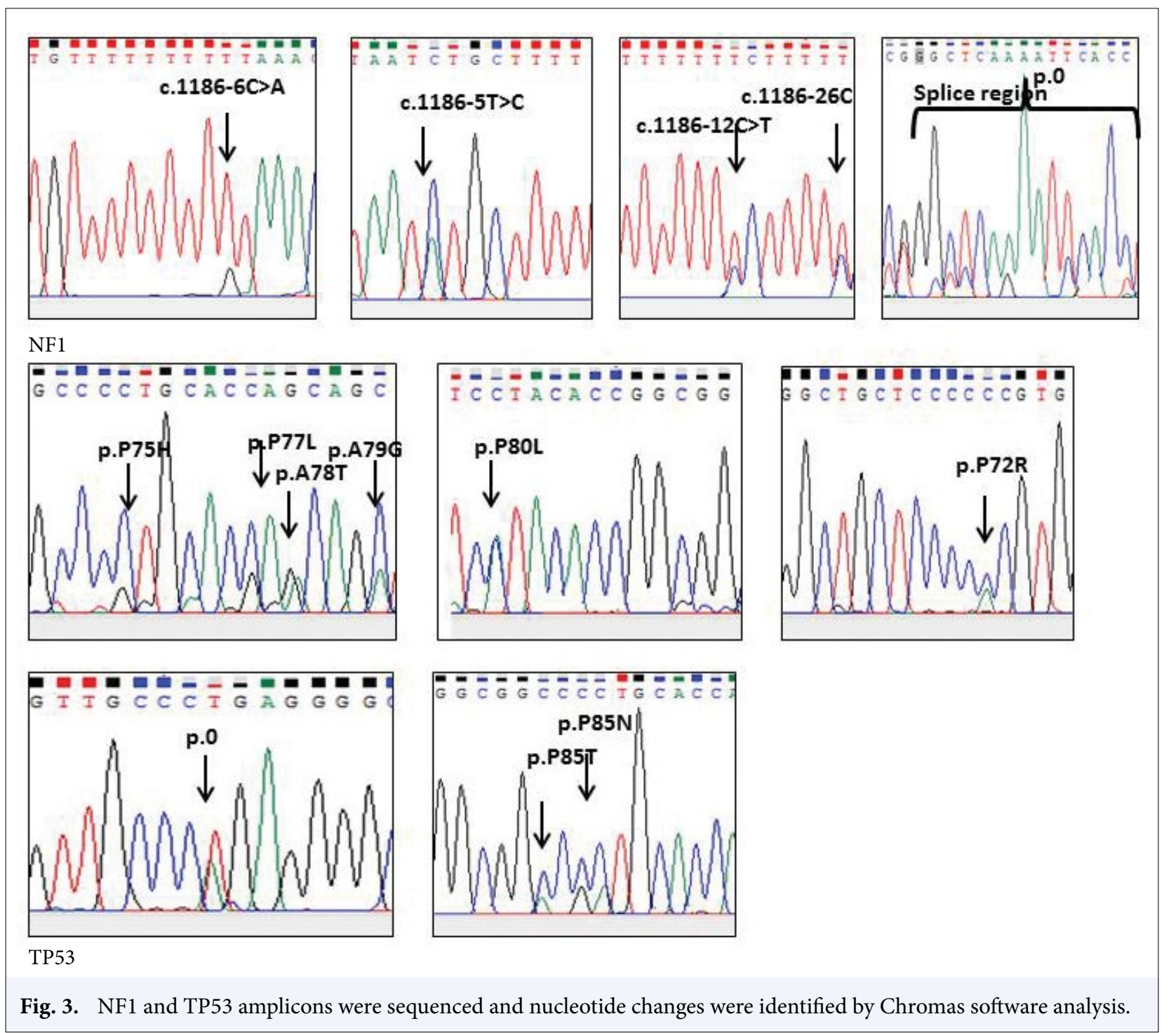

missense mutation (Table 1). All of these changes were in the proline-rich region. This region consists of 60-90 amino acid residues (region rich in proline) located in the N-terminal region and plays an active role in p53controlled apoptosis [15]. Furthermore, the change c.1_* del detected in the splice site was found to be in a nature that could lead to the incorrect expression of gene transcripts.

Two of the changes detected in the NF1 gene (c.1186-5T>C, c.1186-12C >T, c.1186-26C >G, c.1186$6 \mathrm{C}>\mathrm{A}, \mathrm{c} .1215 \mathrm{~A}>\mathrm{G}$ ) were detected as intronic variants in the non-coding region, one of them was synonymous change, and two of them were detected on the splice site sequences (Table 1). In the literature, splicesite mutations have been reported to result in transcript ablation by causing inaccurate expression of gene tran- scription. The localization of the detected changes on P53 and NF1 are given in Figure 4a-b.

\section{Discussion}

Gastric cancer, which is the third most common cause of cancer-related deaths, is an adenocarcinoma, the genomic basis of which has not been fully elucidated, and underlying genetic heterogeneity has been still unclear. Gastric cancer is more common in middleaged and older individuals compared to the young population. Diffuse type gastric carcinoma is known to be more common in young patients, and such cancers are known to have a worse prognosis. On the other hand, intestinal-type gastric carcinoma is more common in the elderly. [16] Gastric cancers tend 


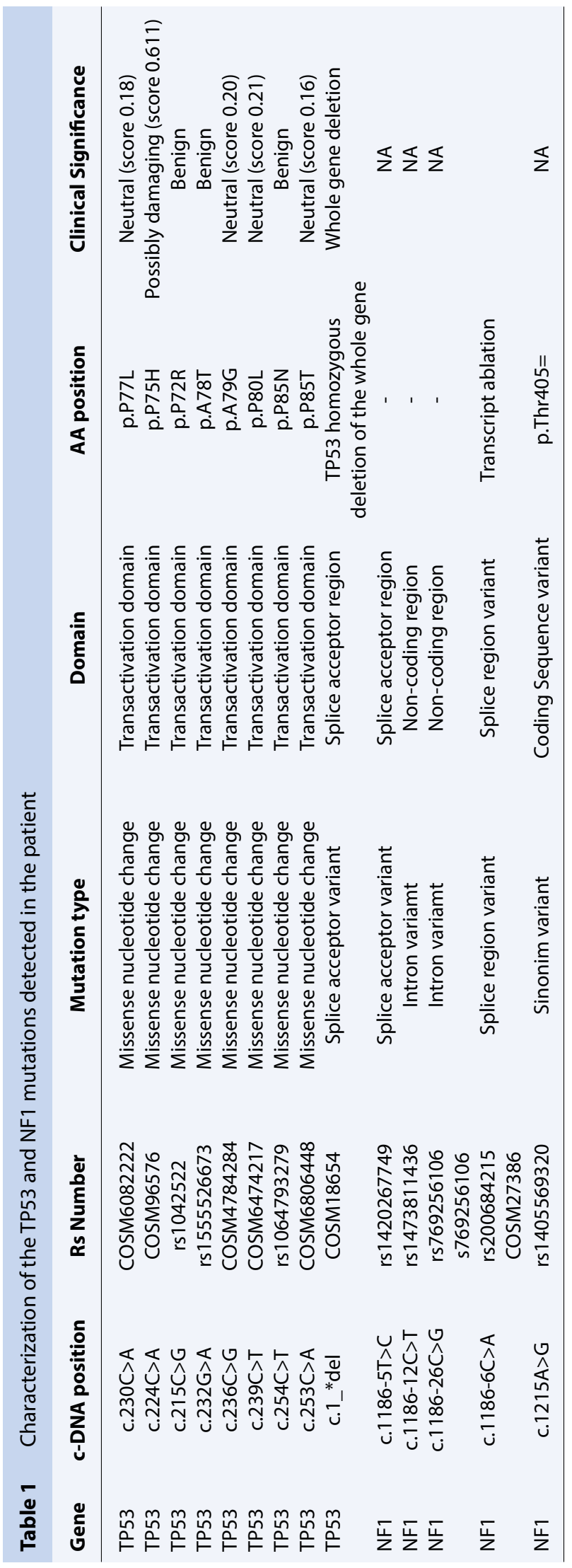

to be more aggressive in young people and women, which suggests a genetic predisposition in this age group.[17] Furthermore, the majority of cases are asymptomatic. Thus it is difficult to diagnose. Nakamura et al. reported in their study published in 2011 that $54.9 \%$ of the young patients with gastric cancer had no complaints, and the diagnosis was made incidentally during examinations. The patient included in our study stated that he only had rapid weight loss and that he did not have any other complaints.[18] Progression and tumor stage affect survival in patients with gastric cancer, and the sensitivity and specificity of the existing noninvasive serological biomarkers are insufficient for both the diagnosis and prognosis. Therefore, early diagnosis and follow-up are very necessary and important in gastric cancer cases. [19, 20] In some studies, the relationship between apoptosis and TP53 changes was evaluated, and it was suggested that the balance between cell proliferation rate and programmed cell death, also called apoptosis, in gastric epithelium maintained homeostasis and that the disruption of the balance between these two processes leading to proliferation of gastric epithelial cells could increase the effects of carcinogens on DNA and the risk of mutational changes. As a result, it might cause gastric cancer development.[21] Recent studies have shown that NF1 is a tumor suppressor that plays a critical role in many types of cancer and has been identified as a prognostic value for patients with gastric cancer. In a study conducted by Liu et al. [11] (2017), immunohistochemical staining and qRT-PCR analysis have revealed that NF1 protein and mRNA levels decrease significantly in cancer tissues compared to healthy tissues. In the present case, mutations causing the formation of the abnormal transcript were detected in the splice region in both TP53 and NF1 genes. Given that splice sites are conserved sequences, point mutations in these sequences may cause false exon and intron recognition, and mutated gene may cause the formation of the abnormal transcript, mutations detected herein can be considered as important. [22,23] The mutations identified through genetic analysis performed in the present study have been found to have the potential of causing structural changes in the end-products of the genes. In particular, P53 and NF1 can be predictive factors in the pathogenesis of SRCC seen at a young age.

\section{Conclusion}

In light of all this data, it is possible to say that molecular analyses may contribute to the diagnostic process, 


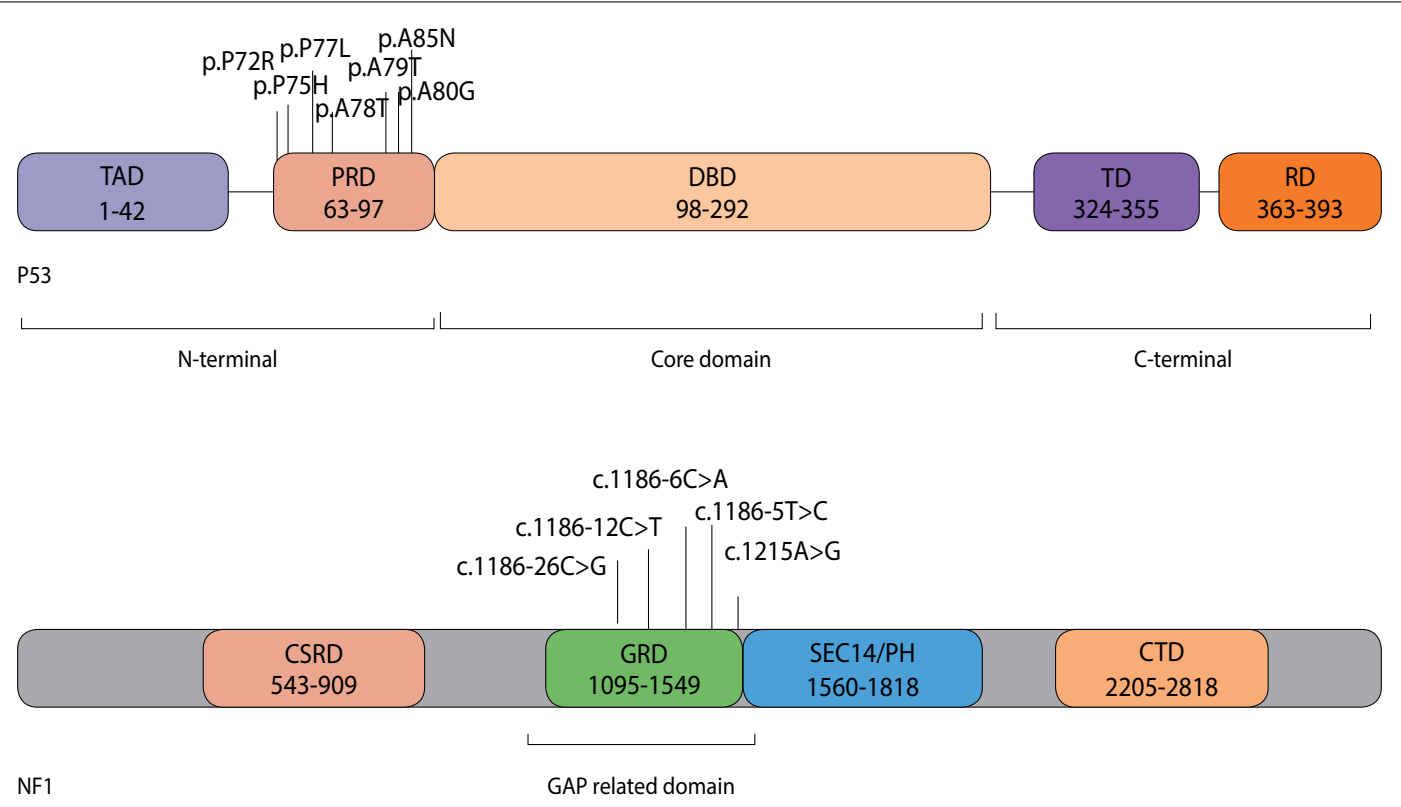

Fig. 4. (a) The structural domains of P53 Protein. Map of the nine TP53 mutations found by DNA sequencing in the patient. The organization of the p53 coding region, including the five major functional domains is shown. (b) The structural domains of NF1 Protein. The organization of the NF1coding region, including the four major functional domains, is shown.

considering the inadequacy of clinical findings and analyses to help diagnose.

Informed consent: A written informed consent was provided by the patient.

Peer-review: Externally peer-reviewed.

Conflict of Interest: No potential conflict of interest was reported by the author.

Financial Disclosure: There is no financial support from any foundation.

Authorship contributions: Concept - M.E., D.F.A.B.; Design - M.E., D.F.A.B., S.H.A.; Supervision - M.E; Materials M.E.; Data collection \&/or processing - M.E., D.F.A.B.; Analysis and/or interpretation - M.E., D.F.A.B., S.H.A.; Literature search - D.F.A.B., S.H.A., T.K.; Writing - M.E., D.F.A.B., S.H.A.; Critical review - M.E., D.F.A.B., S.H.A., T.K.

\section{References}

1. Ferlay J, Colombet M, Soerjomataram I, Mathers C, Parkin DM, Piñeros $M$, et al. Estimating the global cancer incidence and mortality in 2018: GLOBOCANsources and methods. Int $\mathrm{J}$ Cancer 2019;144(8):1941-53.

2. Yalcin S. Gastric cancer in Turkey-a bridge between west and East. Gastrointest Cancer Res 2009;3(1):2932.
3. Şahin M, Tanrıkulu Y, Erel S, Bayraktar K, Akkuş MA. Mide Kanserinde Gastrektomi Deneyimlerimiz. Bidder Tip Bilimleri Dergisi 2010;2:20-6.

4. Cormedi MCV, Katayama MLH, Guindalini RSC, Faraj SF, Folgueira MAAK. Survival and prognosis of young adults with gastric cancer. Clinics (Sao Paulo) 2018;73(suppl 1):e651s.

5. Machlowska J, Pucułek M, Sitarz M, Terlecki P, Maciejewski R, Sitarz R. State of the art for gastric signet ring cell carcinoma: from classification, prognosis, and genomic characteristics to specified treatments. Cancer Manag Res 2019;11:2151-61.

6. Pernot S, Voron T, Perkins G, Lagorce-Pages C, Berger A, Taieb J. Signet-ring cell carcinoma of the stomach: Impact on prognosis and specific therapeuticchallenge. World J Gastroenterol 2015;21(40):11428-38.

7. Levine AJ, Momand J, Finlay CA. The p53 tumour suppressor gene. Nature 1991;351(6326):453-6.

8. Busuttil RA, Zapparoli GV, Haupt S, Fennell C, Wong SQ, Pang JM, et al. Role of p53 in the progression of gastric cancer. Oncotarget 2014;5(23):12016-26.

9. Olivier M, Hollstein M, Hainaut P. TP53 mutations in human cancers: origins, consequences, and clinical use. Cold Spring Harb Perspect Biol 2010;2(1):a001008.

10. Puccini A, Poorman K, Salem ME, Goldberg RM, Shields AF, Xiu J, et al. Comprehensive molecular profiling of signet-ring-cell carcinoma (SRCC) from 
the stomach and colon. Journal of Clinical Oncology 2018;36:4098.

11. Liu D, Zhang Y, Li Y, Fan K. Neurofibromatosis type-1 is a prognostic indicator in human gastric carcinoma. Oncotarget 2017;8(47):82910-9.

12. Trovó-Marqui AB, Tajara EH. Neurofibromin: a general outlook. Clin Genet 2006;70(1): 1-13.

13. Philpott C, Tovell H, Frayling IM, Cooper DN, Upadhyaya M. The NF1 somatic mutational landscape in sporadic human cancers. Hum Genomics 2017;11(1):13.

14. Cichowski K, Jacks T. NF1 tumor suppressor gene function: narrowing the GAP. Cell 2001;104(4):593604.

15. Baptiste N, Friedlander P, Chen X, Prives C. The proline-rich domain of p53 is required for cooperation with anti-neoplastic agents to promote apoptosis of tumor cells. Oncogene 2002;21(1):9-21.

16. Oliveira C, Seruca R, Carneiro F. Genetics, pathology, and clinics of familial gastric cancer. Int J Surg Pathol 2006;14(1):21-33.
17. Chung HW, Noh SH, Lim JB. Analysis of demographic characteristics in 3242 young age gastric cancer patients in Korea. World J Gastroenterol 2010;16(2):256-63.

18. Nakamura R, Saikawa Y, Takahashi T, Takeuchi H, Asanuma H, Yamada Y, et al. Retrospective analysis of prognostic outcome of gastric cancer in young patients. Int J Clin Oncol 2011;16(4):328-34.

19. Bray F, Ferlay J, Soerjomataram I, Siegel RL, Torre LA, Jemal A. Global cancer statistics 2018: GLOBOCAN estimates of incidence and mortality worldwide for 36 cancers in 185 countries. CA Cancer J Clin 2018;68(6):394-424.

20. Mi L, Ji X, Ji J. Prognostic biomarker in advanced gastric cancer. Transl Gastrointest Cancer 2016;5(1):16-29.

21. Yang Y, Deng CS, Peng JZ, Wong BC, Lam SK, Xia HH. Effect of Helicobacter pylori on apoptosis and apoptosis related genes in gastric cancer cells. Mol Pathol 2003;56(1):19-24.

22. Anna A, Monika G. Splicing mutations in human genetic disorders: examples, detection, and confirmation. J Appl Genet 2018;59(3):253-68. 